\title{
An Investigation into Factors Affecting the Use of English Prepositions by Vietnamese Learners of English
}

\author{
Tran Tin Nghi ${ }^{1,3}$, Nguyen Tat Thang ${ }^{2} \&$ Tran Huu Phuc ${ }^{3}$ \\ ${ }^{1}$ Ho Chi Minh City University of Food Industry, Ho Chi Minh city, Viet Nam \\ ${ }^{2}$ Faculty of Foreign Languages, Da Lat University, Viet Nam \\ ${ }^{3}$ University of Foreign Language Studies, The University of Da Nang, Viet Nam \\ Correspondence: Tran Tin Nghi, Ho Chi Minh City University of Food Industry, Ho Chi Minh city, Viet Nam.
}

Received: September 5, 2020

Accepted: September 18, 2020

Online Published: September 22, 2020

doi:10.5430/ijhe.v10n1p24

URL: https://doi.org/10.5430/ijhe.v10n1p24

\begin{abstract}
English prepositions play a significant role in helping students form a well-structured sentence in their learning and communicating. To help Vietnamese learners of English acquire their competence, the authors have done survey research to investigate the factors affecting the uses of English prepositions made by Vietnamese learners of English. The population included 200 female and 200 male participants. A total of 400 answers on the questions provided in the 100-question questionnaire were used for hypothesis testing. The items in the survey were given different weights, and the total attainable marks were 100. The results showed that Vietnamese intra-lingual interference strongly affected prepositional sense expressed by Vietnamese EFL learners. Genders, level of learning (low, intermediate, and advanced), writing and speaking, and cognitive embodiment also played a significant role in terms of language transfer, affecting the usage of English prepositions by EFL learners.
\end{abstract}

Keywords: Language transfer, L1 influence, cognitive linguistics, English prepositions, non-linguistic factors

\section{Introduction}

English prepositions cause many difficulties for learners of English (Saravanan, 2014; Sultan, 2014; Özbay \& Bozkurt, 2017; Heydari \& Bagheri, 2012; Sudhakaran, 2015; AlQbailat, Al-Momani, \& Almahameed, 2016) or they are even considered the most challenging factor in learning this language (Gvarishvil, 2012). The difficulties Vietnamese learners of English face when using English prepositions arise from the differences in Vietnamese and English prepositional system. In English, prepositions are an essential word class with 140 items and almost appear in every sentence while it is hardly defined in Vietnamese (Nguyễn Hoàng Phương, 2010).

Traditional Vietnamese grammarians tend to synchronize Vietnamese prepositions with conjunctions into conjunctions because both Vietnamese conjunctions and Prepositions are used to connect sentence elements. The only difference is inferred that conjunctions are used to connect clause levels, but prepositions for words or phrases. Therefore, the idea of the combination of two kinds of Vietnamese word class is not actively supported. However, the existence of Vietnamese prepositions and their functions is recorded and further studied. Vietnamese prepositions are classified recognized by two kinds: original prepositions, e.g., tại, bới, vì, của, etc. and derivational prepositions (from nouns, e.g., trong, ngoài, đầu, cuối, bên, cạnh, etc. and verbs, e.g., ra, vào, lên, xuống, etc.). The Vietnamese prepositional system is so complicated that Vietnamese learners of English often get confused in the use of English prepositions, e.g.: 'He acrossed the street' instead of 'He walked across the street.'

Since the vast difference lies in the cognition about the surrounding world of two cultures and the languages, which are reflected and organized in the human perception, Vietnamese people tend to transfer some of their cognition from their language, culture, and human experience to the target language. That is why a careful investigation of factors affecting the use of English prepositions is urgent and necessary for language educators.

\section{Literature Review}

The conception of mapping second language words with existing meaning in the first language has been acknowledged to be affected by the ecology and social context of an individual for time (Zhang \& Liu, 2013). The aspect is considered as a positive component in understanding and comprehending the target language. For example, it is easier for adults to learn new language compared to children because they do not need to acquire many concepts 
but new verbal symbols that represent these ideas (Rączaszek-Leonardi, Nomikou, \& Deacon, 2018). A guided context during language learning offers learners an opportunity to learn the differences between concepts and words at the level of explicit knowledge. However, it does not necessarily lead to the implicit or automatic change process in the suggested conceptual level. In regards to the socio-ecological model, adults learn a new language easily because they are more exposed compared to toddlers or teenagers. The new language helps them to gain knowledge to map prevailing concepts obtained through the use of the first language. Given that teaching target language has explicit nature, an individual must consider the level at which the explicit teaching will influence the conceptual streamlining.

Cognitive studies of transfer are entirely new to linguistics recently. Not many researchers have carried on that line of business because it was complicated and intense. Only some of the studies focus on the major lexical categories (Giang \& Khuong, 2014; Borovsky \& Elman, 2006; Netra, 2016), L2 word order processing (Erdocia \& Laka, 2018; Lee, Lu, \& Garnsey, 2013; McDonald, 2008; Cat, Klepousniotou, \& Baayen, 2015), language skills (Tare \& Gelman, 2010; Burchinal, et al., 2000), teaching grammar (Raflis \& Lase, 2018; Tian, 2015; Kermer, 2016), but not for a minor lexical group of words such as prepositions or particles. Few cognitive analyses of preposition have been studied so far; However, the field of these researches are mainly focused on language teaching (Wijaya \& Ong, 2018; Hung, Vien, \& Vu, 2018). That is why the research gap for conceptual transfer is open up at present.

Jarvis and Pavlenko (2008) have developed a conceptual framework for detecting language transfer, also called Cross-linguistic Influence (CLI), concerning factors in its processes and conditions (p. 175). The first category involves linguistic and psycholinguistic factors. The second category mainly mentions the mental, attentional, and developmental factors that link to the cognitive maturity, universal process of SLA, learning attitudes, and attention to the language. The third category related to age, the intensity of language exposure, residence time, language proficiency, and the number and order of acquired languages. The fourth category is all kinds of factors from the language learning environment, and the fifth and last category is related to the language use factors.

After examining and studying several concepts regarding conceptual transfer on CLI, it was appropriate to develop an improved conceptual framework emphasizing on the social-ecological model and biopsychosocial model. The proposed framework embodies the multifaceted interactions that involve mutual repercussions between biological, social, and psychological constructs of the conceptual transfer. The framework suggests that nonlinguistic factors concerning language transfer act as both barriers and facilitators to support psychological, biological, and social effects on an individual's ability to learn a target language. Additionally, the constituents of the framework do have a unidirectional cause-consequence temporality. These aspects have causality systems and processes that influence one another over time and space in an interconnected way.

\section{Methodology}

\subsection{Participants}

This paper aims to examine the English preposition mastery of Vietnamese native speakers. The data are collected from 400 participants from secondary students to adult learners in Vietnam. The participants' ages are above 11. Most of the participants who are spending their academic life in schools or universities must learn English at one of the compulsory subjects at school. English is taught in schools as a school year exit for the next levels in their 9th and 12th grades. The research divided the total of the sample (400 participants, more significant than the minimum must-have number of 385) into four small groups for conducting a study such as secondary, high school, college, and graduate levels with the balance in a quantity of 100. Below are demonstrations for each of the groups.

Table 1. Sample sizes according to graduates

\begin{tabular}{lll}
\hline Graduates & Sample size & Jobs \\
\hline Under 30 & 25 & Multidisciplinary \\
Under 40 & 25 & Multidisciplinary \\
Under 50 & 25 & Multidisciplinary \\
Under 60 & 25 & Multidisciplinary \\
Total & 100 & \\
\hline
\end{tabular}


Table 2. Sample sizes according to universities

\begin{tabular}{lll}
\hline University & Sample size & Major \\
\hline Ho Chi Minh City University of Food Industry & 25 & Multidisciplinary \\
Da Lat University & 15 & Social Science \\
The University of Da Nang - University of & 15 & English Major \\
Foreign Language Studies & & \\
Ha Noi University & 15 & Chinese major \\
Can Tho University & 10 & French Major \\
Others & 20 & Multidisciplinary \\
Total & 100 & \\
\hline
\end{tabular}

Table 3. Sample sizes according to high schools

\begin{tabular}{lll}
\hline Highschool & Sample size & Grades \\
\hline Public & 50 & $10-11-12$ \\
Private & 30 & $10-11-12$ \\
International & 15 & $10-11-12$ \\
Study abroad & 5 & $10-11-12$ \\
Total & 100 & \\
\hline
\end{tabular}

Table 4. Sample sizes according to secondary schools

\begin{tabular}{lll}
\hline Secondary & Sample size & Grades \\
\hline Public & 50 & $6-7-8-9$ \\
\hline Private & 30 & $6-7-8-9$ \\
\hline International & 20 & $6-7-8-9$ \\
\hline Total & 100 &
\end{tabular}

Table 5. Summary of Survey Participants

\begin{tabular}{llllll}
\hline Variable & Observations & Minimum & Maximum & Mean & Std. deviation \\
\hline Female & 200 & 10.000 & 96.000 & 50.547 & 18.526 \\
\hline Male & 200 & 10.000 & 96.000 & 48.622 & 22.109
\end{tabular}

The participants' data are separated into different categories aiming at investigating factors that may affect to CLI on the use of English prepositions by Vietnamese learners of English.

\subsection{Instrumentation}

The questionnaire consists of four parts. The first part is designed to collect all data related to social and psychological factors, language intensity, age, residence time, the number of acquired languages. The second part is a multiple-choice test with the most common English prepositions employed to investigate linguistic factors. The third part is writing with guided words and pictures task to investigate Vietnamese learners of English competence in language use. The last part is the cloze-test to measure the participants' English proficiency in using English proficiency. All tests are administered in one paper test and graded with 100 points. (See the Appendix)

\subsection{Materials}

The materials used in the research are the exercises of 10 units (from unit 13 to unit 22) in Part II of the book entitled English Pronouns and Prepositions (Swick, 2011). Prepositions are chosen for the research because they are sometimes underestimated and thought to be straightforward ones. The number of questions is randomly selected from the book with an equivalent amount. (See appendix). 


\subsection{Statistical Coding}

The deletion of English prepositions was used to assess their overall semantic accuracy and capability to fill in the blanks appropriately in this test. In the first test, the correct answers were coded with digit " 0 " and incorrect answers with the digit "1-3" in order to analyze the frequency of correct and incorrect of the reach of questions. The coding was marked from 0 to 3 , based on the proximity to the correct answer, which was coded 0 . The second and fourth tests were designed to asked participants to describe the place or spatial relation of an item with the other things in the text with the help of the pictures. There were five pictures in total. The questions were given different weights, and the total attainable marks were 100 marks.

\section{Findings and Discussion}

\subsection{Relationship between Vietnamese Intra-Lingual Interference and Prepositional Senses Expressed by Vietnamese EFL Learners}

The study put up the hypothesis that Vietnamese intra-lingual diversity does not relate to prepositional senses shown by Vietnamese EFL learners. Based on the scores obtained from the test questions on the questionnaire, the data were obtained and analyzed using statistical techniques and compared against the score they scored in the multiple-choice test. The marks were ranked from 0 to 100 , according to the way they performed in the multiple-choice test.

From the results obtained, it shows that the mean score of the participants, Vietnamese learners of English, whose English is their second or foreign language, had the lowest with a mean of 56/100 in comparison with other groups whose numbers of acquired languages are more than two. The high standard deviation of 126 about mean meant that there was a massive difference amongst the EFL learners.

Basing on the mean values, it reveals that learners who only study English as their foreign language had difficulties in using English prepositions. This result meant that the Vietnamese Intra-lingual effect has a negative influence on the use of English prepositions.

The outcome, these calculations revealed that intra-lingual diversity had a significant factor in influencing the use of prepositions. It could be noticed that the value of $\mathrm{p} 0.000183$ to be a smaller figure than 0.05 . This result infers that there exists a significant effect of Vietnamese intra-language interference on the use of prepositions.

Table 6. Summary of the ANOVA test on different groups of learners

\begin{tabular}{lllllrc}
\hline ANOVA & \multicolumn{7}{l}{ Source of Variation } & SS & $d f$ & MS & F & P-value & F crit \\
\hline Between Groups & 10171.89 & 2 & 5085.944 & 8.794455 & 0.000183 & 3.01851 \\
Within Groups & 229011.8 & 396 & 578.3126 & & & \\
Total & 239183.7 & 398 & & & &
\end{tabular}

It is evident and essential that in Vietnam, oral and written modalities of their language are a crucial part of social and communication interaction. At homesteads, written and verbal communication are essential, even to a point where young ones are traditionally taught to listen, read, and write their Vietnamese language. In schools, churches, and even public domain activities, it mainly involves people interacting and communicating extensively in Vietnamese. The Vietnamese practice context gives the use of the English prepositions by EFL learners no chance to use them. It seems possible only in the classwork domain that the use of English prepositions is emphasized and reinforced. At this point, there will always exist a conflict between English prepositions, structure, pronunciation, and even spelling to those who only English as their foreign language in comparison with the participants who have more than one acquired language. Still, the difference is very slightly (coefficient range $0.78-0.87$ ). Hence, it can be concluded that some of the participants of the survey have a greater ability in the use of English prepositions (those with at least two foreign languages) while Vietnamese learners of English as their second language only perform with the lower scores. Therefore, there is evidence to show that intra-lingual diversity has a significant effect on the use of English prepositions by Vietnamese EFL learners.

\subsection{Gender Difference in Terms of Negative Transfer when Acquiring English Prepositions}

To test if there exists no significant difference between genders in the use of the prepositions, data on the participants' final score against their respective gender was tabulated. This data were manipulated later with a Chi-Square test. The result from the survey was used to test the hypothesis that gender does not take part in shaping a person's command of the use of English prepositions. Table 5 shows how 200 females and 200 males performed in the use of 
English prepositions. Considering the mean value obtained of 50.547 for females and 48.622 for males, and the standard deviation value of 84.7 show that there is a slight difference between the two genders, with the difference pointing in one direction, implicating that female had better use of English prepositions than male students had. This finding is also evident from the questions $31,48,57,68$, and 72 in the test, where the differences between the female and male performance in the use of English prepositions are noticeable easily. Because most males never attempted these questions, they have difficulties with questions consisting of complex English prepositions. 67\% of male participants failed these questions compared to their female counterparts. Furthermore, the results from the Chi-square test revealed that it is of significance statistically the effect of gender on prepositions choice by Vietnamese EFL learners, as p (0.00062) was less than 0.005 (See Table 7). There exists a difference between male and female performances in the use of English prepositions that do not express themselves enough to be noticed. An explanation that can be given to support this argument is that female students like to express themselves, verbally better than male students. That gives them more exposure to the use of prepositions more often. Female sex tends to use oral learning strategies and social orientation effectively more than males in learning English. The results on the speaking test (interviews) showed that $60 \%$ of female participants performed well while male students managed a score of $49 \%$. Generally, from this study, it can be reported that gender plays a significant role in shaping the use of English prepositions by Vietnamese EFL learners.

Table 7. Summary of Chi-square test on Gender Grade Distributions.

\begin{tabular}{ll}
\hline Chi-square (Observed value) & 48.698 \\
Chi-square (Critical value) & 49.802 \\
DF & 35 \\
p-value & 0.0062 \\
Alpha & 0.05 \\
\hline $\begin{array}{l}\text { As the computed p-value is smaller than the significance level alpha }=0.05, \text { one } \\
\text { rejects the null hypothesis HO. }\end{array}$
\end{tabular}

The results also show that Questions 1-60 were easy questions, while 61-100 were assumed to be problematic questions. From the variance calculated is shows a wide spread of answers given by the participants on the question. The variance range is large (19.16-24.167), meaning the answers given by participants were far from the correct choice.

\subsection{The Tendency of Vietnamese Learners to Use Simple Preposition Rather Than Complex Preposition}

In order to determine the ability of Vietnamese learner's proficiency to comprehend and use simple or complex prepositions, a multiple-choice test was used as a tool to assess the EFL learner's knowledge of their specific structure. Besides, the prepositions in the questionnaire test were based on their frequency they appeared in the Vietnamese education system textbooks. The test included 14 simple questions and 20 complex prepositions. (See table 9). A demonstration in Table 8 shows that the college participants (55.68) performed better than graduate participants (39.87) on the study test did. Furthermore, the reveals that the total mean of all answers by both college participants and graduate participants on both complex and simple prepositions was around 45. These results infer that Vietnamese learners of English have knowledge on the use of English prepositions. Though a small disparity exists in the percentages between college and graduate, there is a statistically important significant disparity between the two groups data in terms of using the English prepositions. The statistical significance (0.0123) is smaller than 0.05 (see Table 10). This reveals that the use of English prepositions by Vietnamese EFL learner's proficiency level plays a crucial role in the understanding of simple and complex prepositions. Tables 4 and 6 show a detailed statistical description of the results. It comprehensively reveals the percentage of false answers on each case on the test (simple and complex prepositions). Considering the performance of both college participants and graduate participants concerning the simple prepositions of one word, it is evident that more than 42.43 (Mean) of the simple prepositions and 52.45 (Mean) are problematic to the EFL learners. The higher portion of incorrect answers for complex prepositions questions in the survey is also consent between college participants $(49.65 \%$ and $55.68 \%)$ and graduates $(36.00 \%$ and $19.87 \%)$. A look at what type of questions were attempted, and those performed well in other questions of the survey was done. There was a tendency of most participants not to attempt questions that seemed hard, and the high variance calculated below could reveal that most had their answers far from the correct choice. This survey shows that Vietnamese EFL learners in this survey have difficulties in their use of complex English prepositions (with more than two-word prepositions). 
Table 8. Results of incorrect answers for Simple Prepositions and Complex Prepositions

\begin{tabular}{llll}
\hline & College & Graduate & Means of total answers (\%) \\
\hline Simple preposition & 49.65 & 36.00 & 42.43 \\
Complex preposition & 55.68 & 39.87 & 52.45 \\
Mean for total answer & 53.4 & 41.54 & 45.65 \\
\hline
\end{tabular}

Table 9. Table showing compound and Simple Prepositions in the Test

\begin{tabular}{ll}
\hline Simple prepositions & Complex prepositions \\
\hline 1. In & 1. according to \\
2. Until & 2. in reference to \\
3. With & 3. ahead of \\
4. After & 4. in regard to \\
5. Before & 5. apart from \\
6. Since & 6. in spite of \\
7. Up & 7. because of \\
8. Over & 8. instead of \\
9. Within & 9. by means of \\
10. Throughout & 10. on account of \\
11. Off & 11. by way of \\
12. For & 12. out of \\
13. At & 13. in back of \\
14. On & 14. up to \\
& 15. in front of \\
& 16. with respect to \\
& 17. in exchange for \\
& 18. as far as \\
& 19. as well as \\
& 20. as a result of \\
\hline
\end{tabular}

Table 10. Table Showing T-Test of Variation between Diploma and Bachelor Students

\begin{tabular}{|c|c|c|c|c|c|c|}
\hline & $\mathrm{N}$ & $\mathrm{M}$ & SD & $\mathrm{T}$ & Df & Sig \\
\hline \multicolumn{7}{|c|}{ Proficiency level (Complex prepositions) } \\
\hline College degree students & 400 & 1.61 & 0.253 & -2.675 & 624 & 0.01 \\
\hline Graduate degree students & 400 & 1.25 & 0.154 & -2.7543 & 624 & 0.01 \\
\hline \multicolumn{7}{|c|}{ Proficiency level (Simple prepositions) } \\
\hline College degree students & 400 & 1.67 & 0.243 & -3.653 & 624 & 0.01 \\
\hline Graduate degree students & 400 & 1.47 & 0.29 & -2.6443 & 624 & 0.01 \\
\hline
\end{tabular}

4.5 Difference Among Low, Intermediate, and Advanced Levels of EFL Learners in Terms of Negative Transfer Impacting on a Specific Preposition Usage

To evaluate the relationship between levels of learning and the use of prepositions, the analysis variants to investigate this was the individual respondent's total scores with the variation of their level of learning. A Chi-Square test was also used here to evaluate the effect. The outcome from the study was to test the hypothesis that no significant difference exists amongst the low, advanced, and intermediate levels of EFL students in the context of transfers that affect the use of English prepositions. The data were separated to examine the performance of 50 low-level 
(secondary and high school), 50 intermediate-level (college) and 50 advanced-level (post-graduate) learners to prepositional use in the study. The results obtained reveal an important and very significant negative relationship between the EFL learners who participated in the survey level of learning and their performance in the questionnaire test given. It was indicated that the participants who sailed from the low level of classes attained higher scores than those from senior classes. These results found here were considered very strange, as the 'critical period' hypothesis cannot justify this outcome because students in this survey started learning English (using prepositions) at the low-level classes. Therefore, participants from the senior level of education should be scoring higher total scores than low-level learners. This necessitates perhaps one to explore into the context of the use of English prepositions critically in order to give relevance to these results from the study. To explain this, students from the lower levels of education had more time learning; reciting and exposure were the daily use of the English prepositions in the Vietnamese education system, at least under the instructions of the teachers. They were better off than their senior counterparts who did not get the pressure to use English prepositions. The factor of exposure and practice played a crucial role here more. The level of learning here reveals that it is not simply the time or number of classes one spends in English. Generally, this meant that the participants from lower-level classes were more able students than those from senior classes. This result explains why low-level learners had managed higher scores than those of intermediate and advanced levels. One can only conclude that way basing on the total group score mean, but an evaluation of the data using the Chi-test determines the significance.

Table 11. Total Score Level of Learning Distribution of independence between levels of learning (low, intermediate and advanced)

\begin{tabular}{ll}
\hline Chi-square (Observed value) & 47.698 \\
\hline Chi-square (Critical value) & 48.802 \\
DF & 35 \\
p-value & 0.00472 \\
Alpha & 0.05 \\
\hline
\end{tabular}

Table 11 illustrates that the p-value is 0.00047, which is smaller than 0.005. This result infers that the level of learning amongst Vietnamese EFL learners has a significant effect on the use of English prepositions. The table 11 shows the distribution between levels of learning and scores in the Chi-Square test. From the descriptive test also, it is noticeable that more of the low-level participants attempted the descriptive analysis, which is 56 participants, compared to a score of 34 for advanced and 26 for intermediate levels of learning.

4.6 Cognitive Embodiment and the Difference among Regions in Terms of Language Transfer Affecting the Usage of Specific Preposition

Participants were asked to describe some pictures drawn on the questionnaire paper briefly. This was to test the interference of using local prepositions by the participants. The Vietnamese learners could only handle around ten common simple prepositions, which accounts for nearly $25 \%$ of the total 45 English spatial prepositions. Thus, it could be noticed that there existed a tendency of participants to be dictated by cognitive embodiment on how or what prepositions to use. Most of the participants were concerned about the world they could see but not the unseen. The most commonly used preposition was 'on" with a frequency of 330 and "in" with 256 in their descriptive essay. Some of the prepositions like "outside, along, through" and "against" were used once. Most of the participants focused much on the 'surface' and simple phrases. They did not know geometric factors that could make them use complex prepositions like "behind," "next to" and even "beyond." The EFL learners regarded that something described is already on or either in the picture drawn. They were never worried about the gaps in which it could be similar to in the same picture.

These three sentences were removed from part 5 of the questionnaire with the mistakes in using the prepositions due to the negative transfers from their native mother languages. It can be revealed that sentences formulated above were negatively interchanged from their native Vietnamese mother tongue dialect, structures, and semiotics when they were told to write. The cause of this effect is that it is from two unrelated cultures in identifying their intelligent embodiment. Generally, Vietnamese persons usually establish themselves as a central point to test some of the things in the universe. They judged objects without their relationship to a position. Prepositions like "on" with fundamental space meaning of to have contact with the surface was lost during the entire action of transferring words from their native languages. If could be assumed "on" the lady as in sentence 2 above, the bulb would have been having contact on the lady's head or at least one of her body parts, and it could be said 'the bulb' is on the ceiling then they would be 
no bulb in the room. This supports the hypothesis that prepositions "over" and "up" that imply sight are mostly used than the prepositions like "beneath" and "below" that lack sight. This is because they are the first to interact with and are easier to remember. In addition, the negative impact of the first language affected those EFL learners who could not identify the positional meaning of the preposition, for example "below" and "in". Because the Vietnamese EFL learners start to interact with English prepositions at school with all the background community experiences, there is likely to be a tendency that competency and development in the use of English prepositions will definitely be affected.

\section{Conclusion}

The paper was to investigate the factors that may affect the use of English prepositions by Vietnamese native speakers. It is essential that six findings from the study contribute some facets to the fields of CLI under the cognitive perspective. From this study, it shows that that Vietnamese intra-lingual interference negatively contributes to prepositional sense expressed by Vietnamese EFL learners. Furthermore, it explains that genders, level of learning (low, intermediate, and advanced), writing and speaking, and cognitive embodiment play a significant role in terms of language transfer, affecting the usage of English prepositions by EFL learners. Also, this study revealed that Vietnamese transfer negatively influences the acquisition and use of English prepositions and has difficulties in using both simple and complex prepositions. For further research in the future, authors suggest the framework for analyzing the conceptual transfer as follow:

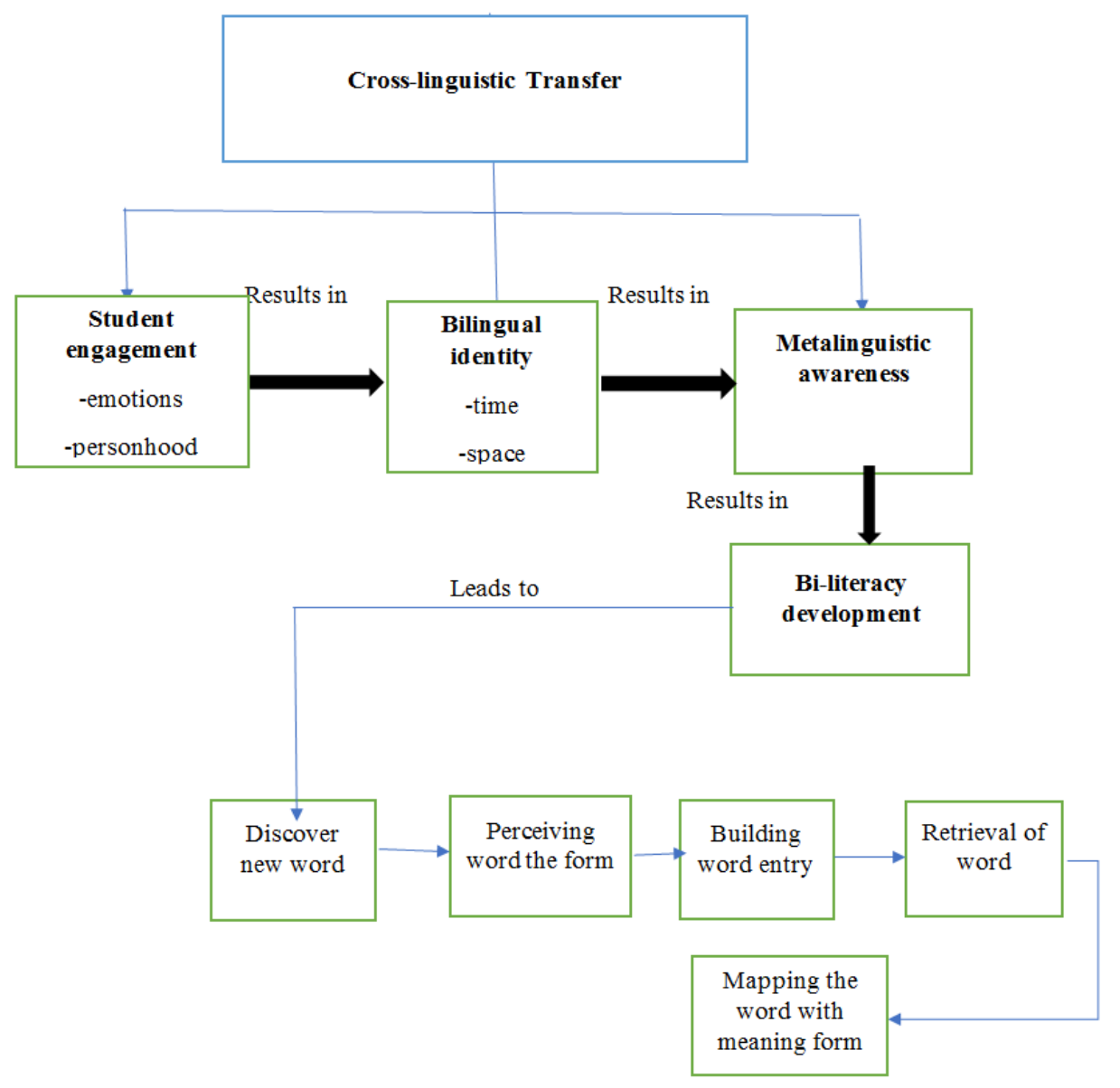

\section{References}

AlQbailat, N. M., Al-Momani, I. M., \& Almahameed, Y. S. (2016). Prepositions in Use: Prepositions of Standard, Prepositions of Possession and Prepositions of Accompaniment. Advances in Language and Literary Studies, 7(4), 1-6. https://doi.org/10.7575/aiac.alls.v.7n.4p.1

Bonvillain, N. (2003). Language, culture, and communication. Upper Saddle River,NJ: Prentice Hall.

Borovsky, A., \& Elman, J. L. (2006). Language input and semantic categories: a relation between cognition and early word learning. Journal of Child Language, 33(4), 759-790. https://doi.org/10.1017/S0305000906007574 
Burchinal, M., Roberts, J. E., Riggins, R., Zeisel, S. A., Neebe, E. C., \& Bryant, D. M. (2000). Relating quality of center-based child care to early cognitive and language development longitudinally. Child Development, 71(2), 339-357. https://doi.org/10.1111/1467-8624.00149

Cat, C. D., Klepousniotou, E., \& Baayen, R. H. (2015). Representational deficit or processing effect? An electrophysiological study of noun-noun compound processing by very advanced L2 speakers of English. Frontiers in Psychology, 6, 77-77. https://doi.org/10.3389/fpsyg.2015.00077

Erdocia, K., \& Laka, I. (2018). Negative Transfer Effects on L2 Word Order Processing. Frontiers in Psychology, 9, 337. https://doi.org/10.3389/fpsyg.2018.00337

Gay, L. R., Mills, G. E., \& Airasian, P. W. (2011). Educational Research: Competencies for Analysis and Applications. California: Pearson.

Giang, T. T., \& Khuong, L. Q. (2014). A Study of Some Linguistic Features of the Transferred Negation of Cognitive Non-Factive Verbs in English. International Journal of Language and Linguistics, II(3), 140-144. https://doi.org/10.11648/j.ij11.20140203.12

Gvarishvil, Z. (2012). Interference of L1 Prepositional Knowledge in Acquiring of Prepositional Usage in English. Akdeniz Language Studies Conference 2012 (pp. 1565-1573). Antalya: Procedia - Social and Behavioral Sciences. https://doi.org/10.1016/j.sbspro.2013.01.224

Hai, L. M., \& Tuoi, P. T. (2009). Vietnamese Lexical Functional Grammar. International Conference on Knowledge and Systems Engineering (pp. 168-171). Ho Chi Minh City: IEEE. https://doi.org/10.1109/KSE.2009.45

Heydari, P., \& Bagheri, M. S. (2012). Error Analysis: Sources of L2 Learners' Errors. Theory and Practice in Language Studies, II(8), 1583-1589. https://doi.org/10.4304/tpls.2.8.1583-1589

Hung, B. P., Vien, T., \& Vu, N. N. (2018). Students' Responses to CL-Based Teaching of English Prepositions. Eurasian Journal of Educational Research, 18(73), 41-58. https://doi.org/10.14689/ejer.2018.73.3

Jarvis , S., \& Pavlenko, A. (2008). Crosslinguistic influence in language and cognition (Vol. 54). New York/London: Routledge. https://doi.org/10.4324/9780203935927

Kermer, F. (2016). A Cognitive Grammar Approach to Teaching Tense and Aspect in the L2 Context. Retrieved from https://amazon.com/cognitive-grammar-approach-teaching-context/dp/1443877662

Lee, E. K., Lu, D. H., \& Garnsey, S. M. (2013). L1 word order and sensitivity to verb bias in L2 processing. Bilingualism: Language and Cognition, 16(4), 761-775. https://doi.org/10.1017/S1366728912000776

McDonald, J. L. (2008). Differences in the cognitive demands of word order, plural, and subject-verb agreement constructions. Psychonomic Bulletin \& Review, 15(5), 980-984. https://doi.org/10.3758/PBR.15.5.980

Murray, N., \& Beglar, D. (2009). Inside track: writing dissertations and theses. New York: Pearson Education Limited . Retrieved from http://wrap.warwick.ac.uk/50686

Netra, I. M. (2016). Lexical Representations of Prototypes of Semantic Primitives in Balinese Tradition and Their Meaning Configuration in English. International Journal of Linguistics, Literature, and Culture, 31-40.

Nguyễn Hoàng Phương. (2010). Chức Năng của Giới Từ Tiếng Việt. Tạp chí Khoa học Giáo dục ĐHSP Tp.HCM, 129-139.

Özbay, A. Ş., \& Bozkurt, S. (2017). Tertiary Level EFL Learners' Use of Complex Prepositions in KTUCLE, TICLE versus LOCNESS. The International Journal of Educational Researchers, 32-41.

Rączaszek-Leonardi, J., Nomikou, I. R., \& Deacon, T. (2018). Language Development from an Ecological Perspective: Ecologically Valid Ways to Abstract Symbols. Language DeEcological Psychology, 30, 39-73. https://doi.org/10.1080/10407413.2017.1410387

Raflis, R., \& Lase, A. (2018). An Analysis of the English Gerund as Subject, Direct Object, Subject Complemet, and Object of Preposition. Journal of Instruction-level Parallelism, 1(2), 60-64. https://doi.org/10.36057/jilp.v1i2.161

Saravanan, J. (2014). The Use of English Prepositions: An Empirical Study. Journal of NELTA, 158-168. https://doi.org/10.3126/nelta.v19i1-2.12089

Seber, G. A., \& Salehi, M. M. (2012). Adaptive Cluster Sampling. https://doi.org/10.1007/978-3-642-33657-7_2

Sudhakaran, B. (2015). Acquisition of English Language Prepositions in the Absence of Formal Grammar Teaching. English Linguistics Research, 88-99. https://doi.org/10.5430/elr.v4n4p88

Sultan, A. I. (2014). Understanding Metaphor in Some English Prepositions. Journal of Historical and Cultural Studies, 6(19), 56-95.

Swick, E. (2011). English Pronouns and Prepositions. New York: he McGraw-Hill. 
Tare, M., \& Gelman, S. A. (2010). Can You Say It Another Way? Cognitive Factors in Bilingual Children's Pragmatic Language Skills. Journal of Cognition and Development, 11(2), 137-158. https://doi.org/10.1080/15248371003699951

Tian, C. (2015). A Cognitive Framework in Teaching English Simple Present. English Language Teaching, 8(3), 24-34. https://doi.org/10.5539/elt.v8n3p24

Vu, D. V. (2017). An Empirical Study on Negative Transfer In Vietnamese Tertiary EFL Learners' English Writing. 2009 International Conference on Knowledge and Systems Engineering, 661-668.

Weinreich, U. (1953). Languages in contact, findings and problems. The Hague: Mouton.

Wijaya, D., \& Ong, G. (2018). Applying Cognitive Linguistics to teaching English prepositions in the EFL classroom. Indonesian Journal of Applied Linguistics, 8(1), 1-10. https://doi.org/10.17509/ijal.v8i1.11456

Zhang, H., \& Liu, Y. (2013). English preposition learning and conceptual transfer: Collocation and colligation of the most frequently used prepositions. Foreign Language Teaching and Research, 568-580.

\section{APPENDIX}

Survey Question for investigating English prepositions uses

\section{PERSONAL INFORMATION}

1. Full name:

2. Your age:

3. Your gender: a. female b. male c.-

4. Your hometown:

5. Your religion:

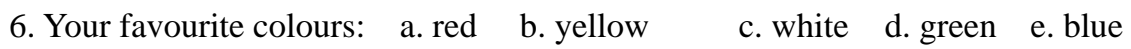

f. orange g. black h. purple i. pink j. brown k. grey

7. How long do you spend reading books? a. hardly b. seldom c. 1-2 hours d. 3-4 hours e. > 4 hours

8. How do you spend your free time?

a. playing games, surfing Facebook, Zalo, reading news, etc. on mobile

b. spending time reading books

c. spending time with family and local community

d. playing sports and outdoor activities

e. others

9. Your background education

a. Secondary School qualification

b. High school qualification

c. Vocational qualification

d. College qualification

e. High education qualification

10. When did you start to learn English?

a. Since primary school

b. Since secondary school

c. Since high school

d. Since college or university

e. others

11. Besides Vietnamese and English, which language can you speak and write well?

Choose the correct answer for each of the questions. 


\section{Prepositions That Indicate Location}

1. A tiny rabbit was hiding a bush.
A. on
B. with
C. to
D. under

2. Please don't sit me.
A. at
B. next to
C. over
D. among

3.

3. We saw several baby birds a nest in that tree.
A. at
B. behind
C. in
D. between

4. There was nothing the plane but empty space.
A. with
B. below
C. to
D. among

5. Father stays the factory until 5:00 P.M.
A. on
B. under
C. above
D. at

6. An angry man stood directly us.
A. at
B. over
C. with
D. in the middle of

7. John stayed me the entire time.
A. beside
B. among
C. in
D. between

8. I saw Maria the many people at the party.
A. under
B. in back of
C. above
D. among

9. There was a huge bug sitting my bed!
A. at
B. with
C. on
D. between

10. I saw a stranger crouching my car and the truck.
A. at
B. above
C. with
D. between

\section{Prepositions That Indicate Movement or Direction}

11. The children ran the gate.
A. toward
B. at
C. in
D. with

12. The young couple strolled the beach.
A. out of
B. along
C. into
D. above

13. The ball rolled the table.
A. at
B. off
C. in
D. between

14. Is Thomas already work?
A. at
B. in
C. to
D. on

15. I was hurrying my desk.
A. at
B. on
C. to
D. in

16. Someone came running the room.
A. onto
B. into
C. above
D. off

17. We slowly drove their house.
A. off
B. on
C. at
D. by

18. Ms. Brown came

England last year.
A. toward
B. at
C. onward
D. from 
19. The poor girl fell bed.
A. out of
B. onto
C. under
D. by

20. I dropped the tools the box.
A. onward
B. into
C. off
D. from

\section{Prepositions That Indicate Time}

21. They left the theater the end of the film.
A. on
B. to
C. before
D. until

22. I should be home ten o'clock.
A. on
B. during
C. by
D. for

23. She only works nine to three.
A. from
B. during
C. at
D. for

24. We always have a picnic the Fourth of July.
A. in
B. to
C. on
D. from

25. Do you always eat lunch noon?
A. on
B. for
C. since
D. at

26. Bill has been sad his fortieth birthday.
A. since
B. to
C. at
D. for

27. Aunt Jane came to town Carmen's big party.
A. to
B. for
C. in
D. on

28. We do a lot of shopping the holiday season.
A. to
B. during
C. by
D. on

29. It's coldest here from December February.
A. to
B. on
C. at
D. in

30. I'm afraid that we'll have to wait tomorrow.
A. until
B. at
C. since
D. to

\section{Compound Prepositions}

31. Some men stood the store.
A. out of
B. instead of
C. in front of
D. up to

32. the forecast, it's going to rain today.
A. Out of
B. According to
C. By means of
D. Instead of

33. his remark, I just said, "Shame."
A. In reference to
B. Ahead of
C. Instead of
D. By way of

34. We stayed home the power outage.
A. out of
B. by way of
C. because of
D. in regard to

35. Do you still live the shop?
A. with respect to
B. by way of
C. in back of
D. in regard to

36. There us stood a large bison.
A. by way of
B. because of
C. ahead of
D. on account of

37. He quickly drove the driveway. 

A. by means of
B. because of
C. out of
D. apart from

38. I was too nervous to walk the president.
A. with respect to
B. in regard to
C. by way of
D. up to

39. It happened your carelessness!
A. with respect to
B. on account of
C. instead of
D. by means of

40. She can't comment that matter.
A. according to
B. by means of
C. up to
D. in regard to

\section{Prepositions That Combine with Other Words}

41. The strange woman was an agent.
A. upheaval
B. bygone
C. downstairs
D. undercover

42. The newly elected governor is a(n) person.
A. downstairs
B. upstanding
C. ingrown
D. bygone

43. She her voice with the anger she felt.
A. intoned
B. upset
C. underwent
D. ingrown

44. They decided to go for dinner.
A. uptown
B. ingrown
C. by and large
D. uphill

45. Did you follow our club's $?$
A. bylaws
B. outlook
C. bylaws
D. insight

46. Her views just aren't
A. uphill
B. up-to-date
C. down-and-out
D. underage

47. The hikers followed the creek
A. up-country
B. downstairs
C. by and by
D. up-country

48. The old man didn't want to his wife.
A. outline
B. outlive
C. outlook
D. up-country

49. My aunt a serious operation last year.
A. up-country
B. upheld
C. underwent
D. installed

50. His look was and his face quite sad.
A. downcast
B. bygone
C. upstanding
D. outlook

\section{Words That Require a Specific Preposition}

51. I began to beg my father more money.
A. for
B. off
C. about
D. of

52. She was being followed a strange man.
A. to
B. on
C. for
D. by

53. Juanita also to our club now.
A. wishes
B. gives
C. depends
D. belongs

54. Don't you want to for a little help?
A. care
B. wish
C. watch
D. ask

55. I never stop worrying my daughter.
A. of
B. about
C. for
D. to 
56. I really care her. I'm in love.
A. for
B. to
C. by
D. at

57. Tom has absolutely no interest jazz.
A. in
B. for
C. at
D. to

58. It's difficult for them to forget the war.
A. on
B. of
C. up
D. about

59. I know I can on your honesty.
A. hope
B. rely
C. plead
D. stay

60. I for a good night's sleep.
A. dream
B. walk
C. long
D. plead

\section{Prepositions and Phrasal Verbs}

61. It's cold. The heat probably off.
A. is
B. on
C. are
D. ask

62. If you ask , you'll get his address.
A. out
B. around
C. with
D. to

63. The old woman was something again.
A. up to
B. onto
C. about
D. into

64. She was too timid to Juan out.
A. look
B. be
C. ask
D. out of

65. The scientist knew she was something.
A. in
B. onto
C. out of
D. up

66. My lawyer won't be until noon.
A. off
B. out of sight
C. on
D. in

67. Your parents are so up-to-date and
A. with it
B. around
C. onto something
D. in it

68. Why was the TV all night?
A. up to something
B. to
C. on
D. out

69. The detective believed she was up
A. and around
B. with it
C. off
D. to no good

70. He wants to take a shower, but the water is again.
A. on
B. onto
C. off
D. to

\section{Phrasal Verbs as Participles}

71. Jim came through me again.
A. on
B. up
C. with
D. for

72. Let's get on the meeting.
A. at
B. with
C. back
D. to

73. The drowsy woman came very slowly.
A. at
B. onto
C. up with
D. to

74. The children came a little cottage in the woods. 

A. upon
B. at
C. off
D. off

75. I work all afternoon. I get 5:00 P.M.
A. off at
B.
C. back at
D. into it

76. Ms. Brown with a wonderful slogan.
A. comes to
B. came at
C. came up
D. has come upon

77. Hurry! You're behind in your work.
A. getting
B. got
C. pushing
D. coming

78. How can I get this deal?
A. back up
B. behind in
C. in on
D. on with

79. The two boys got after school.
A. up with
B. into it
C. back at
D. on with

80. She got us for gossiping.
A. up with
B. on with
C. on with
D. back at

\section{Cloze-Test}

Read the following story and fill in each gap with the most suitable preposition in the box. the MA

$163(\mathbf{8 4})$ Wildstone for about $12 \mathrm{~km}$. Go (85) the town

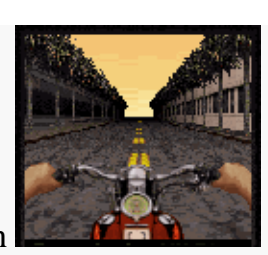

until you get (86) the
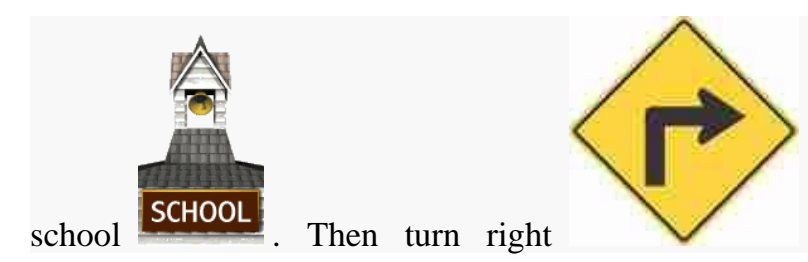

.Go (87)

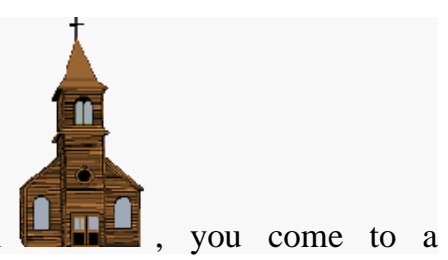

roundabout

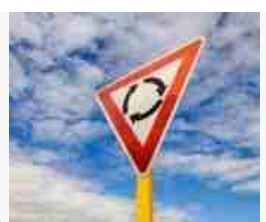

ride on in the direction of Greenhurst. Keep straight on till a crossroads. Go (88)

the lights

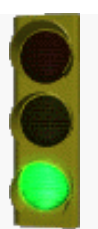

Ride (89)

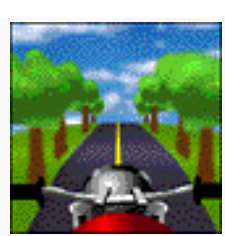

for another $5 \mathrm{~km} \mathbf{( 9 0 )}$ 


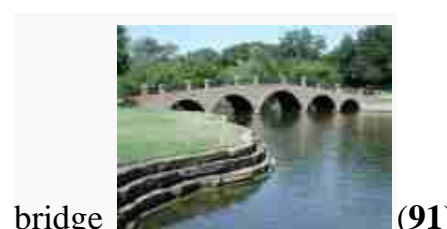

bridge

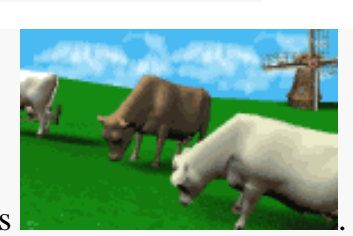

meadows the river, (92)

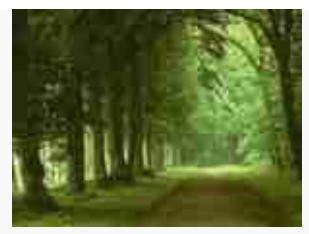

(93) the

You'll see a windmill in the distance.

You'll get (94) the castle very soon. You can't miss it

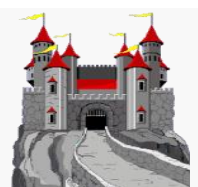

8 pm. Don't be late.

\section{Participial Prepositions}

Rewrite each sentence changing the italicized preposition to a participial preposition.

Example: The group spent hours on this issue.

The group spent hours considering this issue.

96. We'll need to put in a lot of time on this problem.

97. I had a lot to tell about the crimes he had committed.

98. I wanted to speak to her about our future together.

99. Maria passed every test except the one in math.

100. The picnic will go on as planned after the rainstorm.

\section{IV - Picture descriptions}

Choose one the following pictures and describe it in your own words.

\section{Picture A}

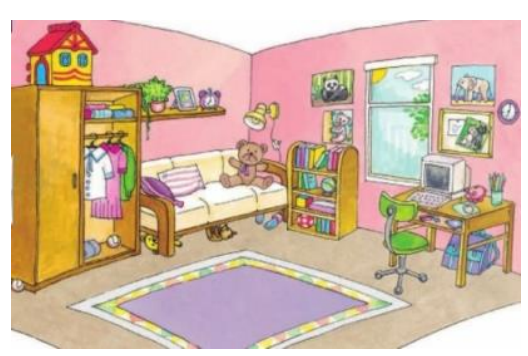

\section{Picture B}

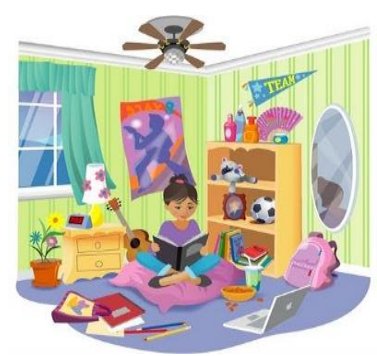




\section{Picture C}

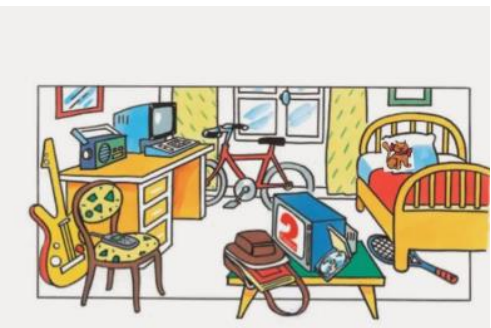

\section{Picture D}

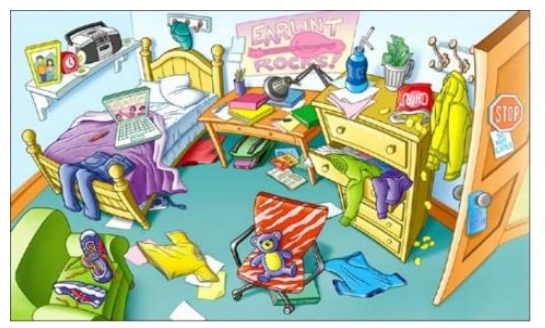

\section{Picture E}

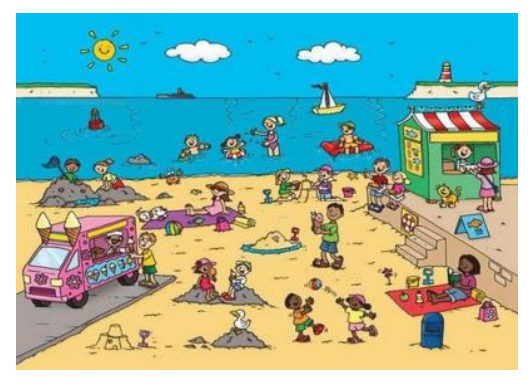

\section{Copyrights}

Copyright for this article is retained by the author(s), with first publication rights granted to the journal.

This is an open-access article distributed under the terms and conditions of the Creative Commons Attribution license (http://creativecommons.org/licenses/by/4.0/). 